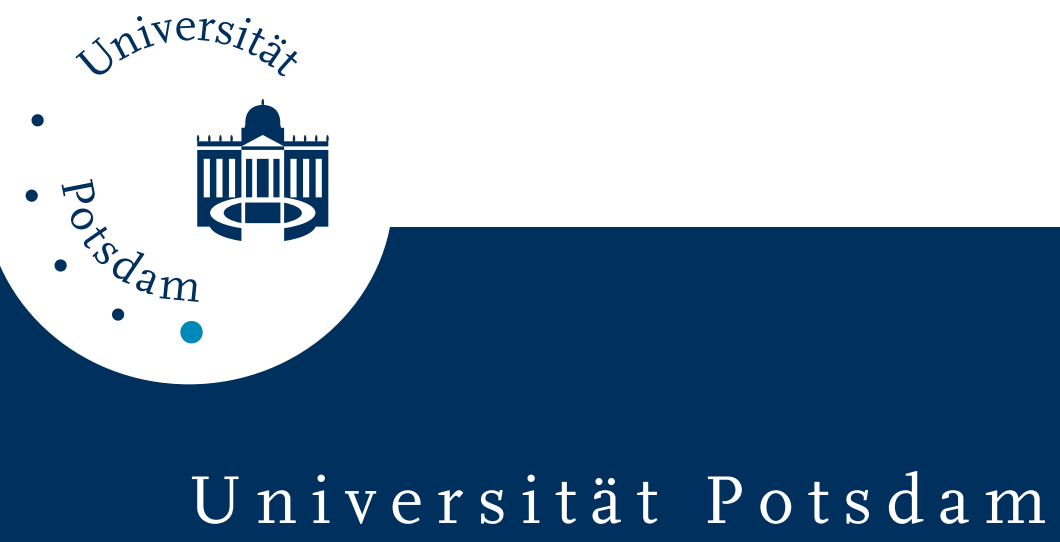

Peter Köberle, André Laschewsky

\title{
Hybrid materials from organic polymers and inorganic salts
}

first published in:

Macromolecular Symposia; 88 (1994) S. 165-175, ISSN 1022-1360

Postprint published at the Institutional Repository of Potsdam University:

In: Postprints der Universität Potsdam

Mathematisch-Naturwissenschaftliche Reihe ; 86

http://opus.kobv.de/ubp/volltexte/2008/2688/

http://nbn-resolving.de/urn:nbn:de:kobv:517-opus-26884

Postprints der Universität Potsdam

Mathematisch-Naturwissenschaftliche Reihe ; 86 
HYBRID MATERIALS FROM ORGANIC POLYMERS AND INORGANIC SALTS

\author{
Peter Köberle and André Laschewsky*\# \\ Institut für Organische Chemie, Universität Mainz \\ Becher-Weg 18-20, D-55099 Mainz (Germany) \\ \#present address: Dept. of Chemistry, University of Louvain \\ Place L.Pasteur, 1, B-1348 Louvain-la-Neuve (Belgium)
}

Abstract: The prepaparation of amorphous, homogeneous blends of zwitterionic polymers and transition metal salts was investigated. Homogeneous miscibility was achieved in many cases up to equimolar amounts of salt, depending on the anion and cation chosen. Various analytical techniques point to a solid state solution of the inorganic ions in the polymer matrix.

\title{
INTRODUCTION
}

The preparation of polymer blends is often troubled by the limited miscibility of polymers with additives. This is particularly true for mixtures with inorganic components, though inorganic-polymer hybrids represent very interesting materials, e.g. with unusual optical, electrical or mechanical properties (Ref.1).

Taking advantage of electrostatic interactions by using zwitterionic polymers, i.e. polymers bearing equal numbers of cations and anions, their simultaneous interaction with all ions of low molecular weight salts added in solution has been known for long (Ref.2), and should also favour miscibility in bulk, as idealized in Fig.1.

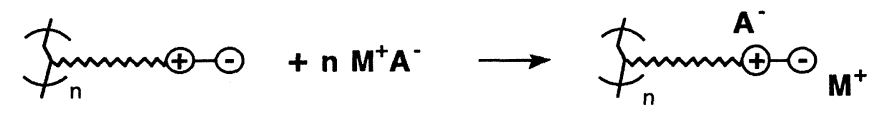

Fig.1 Simple scheme of interaction of polyzwitterions and inorganic salts $M^{+} A^{-}$. 
Indeed, non-crystalline blends with up to stoichiometric amounts of salt have been prepared recently with poly(sulfobetaine)s when appropriate salts were used (Refs.3-6). Further, using hydrophobically modified polyzwitterions, lamellar superstructures could be induced (Refs.4,6).

Miscibility was found to be very selective, depending on the anions as well as on the cations employed, and further, on the detailed structure of the polymer (Ref.6). But so far, little has been known about the detailed structure of the blends, e.g. about the position of the inorganic ions. Hence, we have continued our previous investigations on the zwitterionic polymer poly-1 derived from methacrylate $\underline{1}$ as model compound. Copolymerizing $\underline{1}$ and the zwitterionic dye $\underline{\mathbf{2}}$ of solvatochromic character to give $\underline{\mathbf{C o}-\mathbf{3}}$, a probe was incorporated into the polymer (Fig.2).

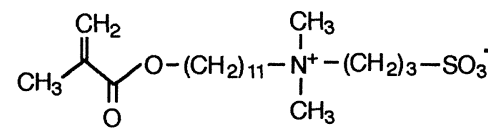<smiles>C=C(C)C(=O)OC[14CH2][14CH2]N(C)c1ccc(N=Nc2ccc[n+](C)c2)cc1</smiles>

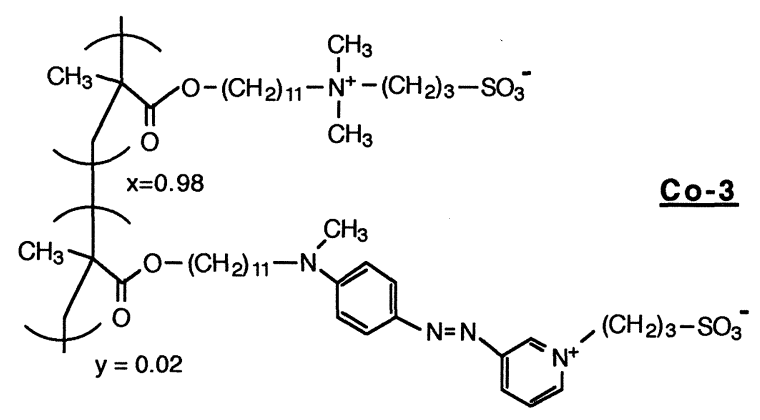

Fig.2 Monomers and polymers studied 


\begin{abstract}
Alternatively, we have studied mixtures with salts of transition metals, which have not yet been reported so far. These investigations do not only extend our understanding of the rules for efficient mixing, but due to some characteristic properties (e.g. magnetic ones), transition metal ions may serve simultaneously as probes for the position and the arrangement of inorganic ions within the blends.
\end{abstract}

\title{
EXPERIMENTAL PART
}

The synthesis of monomer $\underline{1}$ was described previously (Ref.7).

\section{3-[(3'-(N-methyl-N-11-methacryloylundecyl-4-aminophenyl)azopyridinio] propane- sulfonate 2}

Heating equimolar amounts of $\mathrm{N}$-methylaniline and 11 -bromoundecanol at $100^{\circ} \mathrm{C}$ for $36 \mathrm{~h}$, and subsequent treatment after cooling with aq $\mathrm{NaOH}$ gives $\mathrm{N}$-methyl-N-11-hydroxyundecylaniline which is purified by distillation in vacuo (b.p. $=175^{\circ} \mathrm{C}$ at $0.2 \mathrm{mmHg}$ (uncorrected), yield $45 \%, \mathrm{n}_{\mathrm{D}}{ }^{20}=1.5220$ ). Its coupling with diazotated 3 -aminopyridine in aqueous $\mathrm{HCl}$ following standard procedures (Ref.8) gives 3'-(N-methyl-N-11-hydroxyundecyl-4-aminophenyl)azopyridine as red powder after purification by flash-chromatography (eluent: ethyl acetate), in $34 \%$ yield. The esterification with methacryloyl chloride is performed in dichloromethane/ $\mathrm{Na}_{2} \mathrm{CO}_{3}$ analogously to the literature (Ref.7). $1 \mathrm{~g}$ (2.2mmol) of the resulting 3'-(N-methyl-N-11-methacryloylundecyl-4-aminophenyl)azopyridine, $0.27 \mathrm{~g}(2.2 \mathrm{mmol})$ of propanesultone and $0.1 \mathrm{ml}$ of nitrobenzene are refluxed under nitrogen in $70 \mathrm{ml}$ of dry acetonitrile for $3 \mathrm{~d}$. On cooling, red crystals of the zwitterionic dye monomer $\underline{\mathbf{2}}$ precipitate, which are washed with dry diethyl ether and are recrystallized from acetonitrile. Yield: $1.2 \mathrm{~g}$ deeply red crystals $(95 \%)$; decomposition > $200^{\circ} \mathrm{C}$; FD-mass spectrum: peak at $573.4\left(\mathrm{M}+1^{+}\right)$.

${ }_{1} \mathrm{H}$ NMR $\left(400 \mathrm{MHz}, \mathrm{CDCl}_{3}\right): \delta$ (in ppm) $=1.2-1.4 \mathrm{~m}\left(14 \mathrm{H},-\left(\mathrm{CH}_{2}\right)_{7}\right), 1.55-1.70 \mathrm{~m}(4 \mathrm{H}$, $\left.-\mathrm{COO}-\mathrm{C}-\mathrm{CH}_{2},-\mathrm{CH}_{2}-\mathrm{N}<\right), 1.90 \mathrm{~s}\left(3 \mathrm{H}, \mathrm{CH}_{3}-\mathrm{C}(\mathrm{COO}-)=\mathrm{C}\right), 2.59 \mathrm{~m}\left(2 \mathrm{H},-\mathrm{N}^{+}-\mathrm{C}-\mathrm{CH}_{2}-\mathrm{C}_{-} \mathrm{SO}_{3}\right)$ $2.95 \mathrm{t}\left(2 \mathrm{H},-\mathrm{CH}_{2}-\mathrm{SO}_{3}\right), 3.08 \mathrm{~s}\left(3 \mathrm{H}, \mathrm{Aryl}-\mathrm{N}-\mathrm{CH}_{3}\right), 3.40 \mathrm{t}\left(2 \mathrm{H},-\mathrm{CH}_{2}-\mathrm{N}-\mathrm{Aryl}\right), 4.10 \mathrm{t}(2 \mathrm{H}$, $\left.-\mathrm{COO}-\mathrm{CH}_{2}-\right), 5.13 \mathrm{~m}\left(2 \mathrm{H},>\mathrm{N}^{+}-\mathrm{CH}_{2}-\right), 5.51 \mathrm{~m}(1 \mathrm{H},-\mathrm{CH}=\mathrm{C}-\mathrm{COO}-\operatorname{trans}), 6.07 \mathrm{~m}(1 \mathrm{H}$, $-\mathrm{CH}=\mathrm{C}-\mathrm{COO}-\mathrm{cis}), 6.58 \mathrm{~d}(2 \mathrm{H}$, ortho- $\mathrm{CH}$ aniline), $7.82 \mathrm{~d}(2 \mathrm{H}$, meta- $\mathrm{CH}$ aniline), $8.1 \mathrm{~m}$, $8.57 \mathrm{~d}, 9.15 \mathrm{~s}, 9.33 \mathrm{~d}(4 \mathrm{H}$, pyridinium).

${ }^{13} \mathrm{C} \mathrm{NMR}\left(100.6 \mathrm{MHz}, \mathrm{CDCl}_{3}\right.$, spin-echo), $\delta$ in ppm: 18.3 (=C( $\left.\left.\mathrm{CH}_{3}\right)-\mathrm{COO}-\right), 25.9\left(-\mathrm{N}^{+}\right.$ $\left.\mathrm{C}-\mathrm{CH}_{2}-\mathrm{C}-\mathrm{SO}_{3}\right), 27.0,27.1,28.0,28.6,29.2,29.4,29.5\left(-\left(\mathrm{CH}_{2}\right)_{9}-\right), 38.9(>\mathrm{N}-\underline{\mathrm{CH}} 3), 46.9$ $\left(\mathrm{CH}_{2}-\mathrm{SO}_{3}\right), 52.8\left(-\underline{\mathrm{CH}}_{2}-\mathrm{N}<\right), 60.8\left(>\mathrm{N}^{+}-\underline{\mathrm{CH}}_{2-}\right), 64.8\left(-\mathrm{COO}-\underline{\mathrm{CH}}_{2}-\right), 111.5,125.2,127.5$, 
$128.9,135.2,136.5,139.1,143.1,144.2,151.5,153.6$ (-C-Aryl, $\left.-\underline{C H}_{2}=\underline{C}-\mathrm{COO}-\right)$, 167.6 (-COO-).

Monomer 1 was homopolymerized in ethanol at $70^{\circ} \mathrm{C}$ using the initiator $2,2^{\prime}$ azoisobutyronitrile AIBN to give poly-1, and purified as described previously (Ref.7). Dye monomer $\underline{2}$ failed to homopolymerize using AIBN, but could be polymerized in water under micellar conditions using the initiator 2,2'azobis(2-methyl-N-2-hydroxyethyl)propionamide for $24 \mathrm{~h}$ at $85^{\circ} \mathrm{C}$ yielding an insoluble product polv-2.

For copolymerization, $2 \mathrm{~g}(4.9 \mathrm{mmol})$ of $\underline{1}$ and $0.056 \mathrm{~g}(0.1 \mathrm{mmol})$ of $\underline{\mathbf{2}}$ dissolved in $44 \mathrm{ml}$ of $90 \%$ aqueous ethanol were reacted at $70^{\circ} \mathrm{C}$ for $24 \mathrm{~h}$ in presence of $16.2 \mathrm{mg}(2 \mathrm{~mol} \%)$ of AIBN. After evaporation of most of the solvent, the swollen residue is repeatedly extracted with hot ethanol, dissolved in water and lyophilized. Yield: $1.6 \mathrm{~g}(68 \%)$ red polymer $(\underline{\mathbf{C O}-3})$.

Powders of polymer-salt mixtures were prepared by mixing the appropriate quantities of aqueous solutions of the polymer and the salt studied, and lyophilization of the transparent solutions obtained (Ref.6). Pure metal salts used as references were treated identically. Films were obtained by casting from aqueous or trifluoroethanol solutions.

\section{$\underline{\text { Methods }}$}

NMR-spectra in solution were recorded by an Aspect 3000 spectrometer $(400 \mathrm{MHz}$ Bruker). UV-Vis spectra were recorded with a Lambda 5 spectrometer (Perkin-Elmer), IR spectra by a 5DXC FT-IR spectrometer (Nicolet). Thermogravimetry was performed on a thermogravimetric analyzer TGS-2 (Perkin-Elmer), with a heating rate of $10^{\circ} \mathrm{C} / \mathrm{min}$ in nitrogen atmosphere. Differential scanning calorimetry d.s.c was performed with a Perkin-Elmer DSC2, applying heating and cooling rates of $10^{\circ} \mathrm{C} / \mathrm{min}$. X-ray scattering experiments were done with a diffractometer Kristalloflex (Siemens), using the Ni-filtered $\mathrm{Cu}-\mathrm{K}_{\alpha}$-line $(\lambda=0.1541 \mathrm{~nm})$. Refractive indices were taken at $632.8 \mathrm{~nm}$. For details of the Mössbauer spectroscopy (Ref.9), ellipsometric (Ref.10), magnetic (Ref.11) and solid-state NMR studies (Ref.12), see the corresponding references. 


\section{RESULTS AND DISCUSSION}

\section{General characteristics of the polymers}

The solubilities of poly-1, some solution properties and some bulk properties have been described in detail before (Ref.7). Poly-1 is e.g. soluble in warm water and in trifluoroethanol. In bulk, it represents a hygroscopic solid which shows no glass transition up to the decomposition temperature of ca. $230^{\circ} \mathrm{C}$. Its powder diffractograms show two characteristic small angle signals ("pattern A" Ref.6) which are attributed to a complex lamellar superstructure (Refs.7,13,14).

Dye polymer poly-2 is a red powder for which no solvent could be found, being even insoluble in trifluoroethanol which is a common solvent for polymeric sulfobetaines (Ref. 15). Whether this is due to strong attractive interactions of both the betaine moiety and the aromatic groups (see Ref.7), or due to crosslinking is unclear. But the latter seems more probable, as no swelling was observed. As for polv-1, no glass transition up to the decomposition temperature of ca. $230^{\circ} \mathrm{C}$ is observed. X-ray powder diffractograms show the noncrystalline character of poly-2 , but exhibit characteristic small angle signals at $2.2^{\circ}$ and $4.4^{\circ}$. As the intensity of the peaks decreases with the scattering angle, and the corresponding distances of $4.0 \mathrm{~nm}$ and $2.0 \mathrm{~nm}$ calculated by Bragg's equation are correlated by the factor $1 / \mathrm{n}$, the peaks may be assigned as first and second order reflections of a simple lamellar structure, as seen for polymeric pyridiniosulfonates (Ref.7, see also "pattern B" in Ref.6).

The composition of copolymer $\underline{\mathbf{C o - 3}}$ was analyzed by Vis-spectroscopy. Using the extinction coefficient $\varepsilon=4.3 \times 10^{4} \mathrm{l} \cdot \mathrm{cm}^{-1} \cdot \mathrm{mol}^{-1}$ determined for monomer $\underline{\mathbf{2}}$ in $50 \%$ aqueous ethanol containing $1.5 \mathrm{~g} \mathrm{NaI} / 1$, the mole fraction of $\underline{\mathbf{2}}$ in the copolymer was found to be 0.017 . Due to this small content of dye comonomer, $\underline{\mathbf{C o}-3}$ showed nearly the same solution properties and bulk properties as homopolymer poly-1.

\section{Miscibility with Salts of Transition Metals}

Several salts of transition metals were tested for solid state mixtures with zwitterionic poly-1 in stoichiometric and in equimolar amounts. The resulting mixtures were studied by $\mathrm{X}$-ray scattering. In the case of incompatibility or of incomplete mixing, residual signals of the salt are visible in the diffractograms, and the small angle scattering pattern 
of the polymer stays unchanged. In the case of complete mixing, all signals characteristic of the salt have disappeared, and additionally, the small angle scattering pattern of the polymer is transformed from "pattern A" to "pattern B" (Refs. 5, 6, 13). The underlying reorganization of the polymer between two lamellar superstructures has been analyzed in detail previously (Refs.13, 14). The result of the mixing studies are listed in Tab.1 which illustrates the selectivity of the process.

Tab.1 Miscibility of homopolymer poly-1 with equimolar amounts of transition metal salts in bulk, studied by X-ray diffraction.

\begin{tabular}{|c|c|c|c|c|c|c|c|c|}
\hline $\begin{array}{c}\text { CATION } \\
\text { ANION }\end{array}$ & $\mathrm{Na}^{+}$ & $\mathrm{Cr}^{3+}$ & $\mathrm{Mn}^{2+}$ & $\mathrm{Fe}^{3+}$ & $\mathrm{Co}^{2+}$ & $\mathrm{Ni}^{2+}$ & $\mathrm{Cu}^{2+}$ & $\mathrm{Ag}^{+}$ \\
\hline $\mathrm{SO}_{4}^{2-}$ & - & & & - & & & & \\
\hline $\mathrm{Cl}^{-}$ & - & & ++ & ++ & - & & ++ & \\
\hline $\mathrm{NO}_{3}^{-}$ & ++ & ++ & ++ & & ++ & ++ & & ++ \\
\hline $\mathrm{Br}^{-}$ & ++ & & & & & & ++ & \\
\hline $\mathrm{I}^{-}$ & ++ & & & & & & & \\
\hline \multicolumn{8}{|c|}{} \\
++ \\
+
\end{tabular}

First of all, Tab.1 demonstrates that miscibility of polybetaines with inorganic salts in stoichiometric amounts is not restricted to main group elements. To the contrary, it seems that selected salts of most transition metal salts are miscible. As observed for salts of alkali metals, homogeneous mixing depends on both cation and anion employed (Refs.5, 6). Miscibility depends not directly on the charge density, as some bivalent or trivalent ions are less suited than some monovalent ones. It rather seems to follow the Hofmeister lyotropic series for the anions (Refs. 2, 5, 6). Most noteworthy for many salts of transition metals tested, homogeneous mixing goes much beyond the uptake of stoichiometric amounts which has been described before (Refs.3-6), but is feasible in equimolar ratios of ions, e.g. 1 mole of $\mathrm{Mn}\left(\mathrm{NO}_{3}\right)_{2}$ or 1 mole of $\mathrm{FeCl}_{3}$ per betaine group. Hence, the scheme of Fig. 1 appears oversimplified, and homogeneous hybrid materials with a very high fraction of inorganic material can be prepared, opening a great potential of interesting properties. E.g. ellipsometric studies (Ref.16) of transparent cast films prepared from 
stoichiometric blends of poly-1 and NaI show a refractive index $n_{D}$ of 1.654 which is right between the index of poly-1 $\left(n_{D}=1.539\right)$ and $\mathrm{NaI}\left(\mathrm{n}_{\mathrm{D}}=1.775\right)$.

\section{The Structure of Polymer-Salt Blends}

The structure of some polybetaine-salt blends was investigated by X-ray scattering in the past (Refs.6,13). The results indicated an incorporation of the ions in the vicinity of the betaine groups, thus promoting microphase separation. But little is known about the detailed local environment and character (isolated vs. clustered etc.) of the ions.

FT-IR spectroscopy and solid state ${ }^{13} \mathrm{C}$ NMR-spectroscopy of the polymer-salt blends did not show significant differences between pure poly-1, phase separated mixtures (e.g. poly-1 and $\mathrm{NaF}$ ) and homogeneous mixtures of poly-1 and salts (e.g. poly-1 and $\mathrm{NaNO}_{3}$ ) (Ref.17).

Copolymer $\underline{\text { Co-3 }}$ bearing a zwitterionic chromophor was used to study interactions of the betaine groups with inorganic anions via halochromy. In aqueous solution, the absorbance maximum $\lambda_{\max }$ of $502 \mathrm{~nm}$ is only affected by a very large excess of some salts added such as $\mathrm{KI}$ or $\mathrm{NaI}$ (Fig.3), and to a lesser degree by $\mathrm{NaBr}$, but virtually not by $\mathrm{NaF}, \mathrm{NaCl}$ or $\mathrm{NaNO}_{3}$. The halochromic effects go well along with increasing interactions according to the Hofmeister series (Ref.18). No significant halochromic effects of the cations were observed, as may be expected from the structure of dye $\underline{\mathbf{2}}$ having only the cationic group directly linked to the chromophor.

In bulk, $\lambda_{\max }$ of $502 \mathrm{~nm}$ of the pure polymer corresponds to the one in solution, pointing to an environment of similar polarity. However, stoichiometric amounts of $\mathrm{NaI}$ are sufficient to provoke a significant halochromic effect in bulk, yielding a $\lambda_{\max }$ of $507 \mathrm{~nm}$ which is comparable to solutions containing a very large excess of NaI (Fig.3). Hence, the iodide anion is probably positioned in the close vicinity of the pyridinium group. Whether this is true for other anions as well, is not clear.

Some information about the cations in the blends can be gained from particular properties of the transition metals used. Mössbauer-spectroscopy was applied to blends containing 1 mole of $\mathrm{FeCl}_{3}$ per betaine group which are homogeneous according to $\mathrm{X}$-ray studies, as illustrated in Fig.4 (Ref.19). The spectra of the pure salt which is treated identically to the 


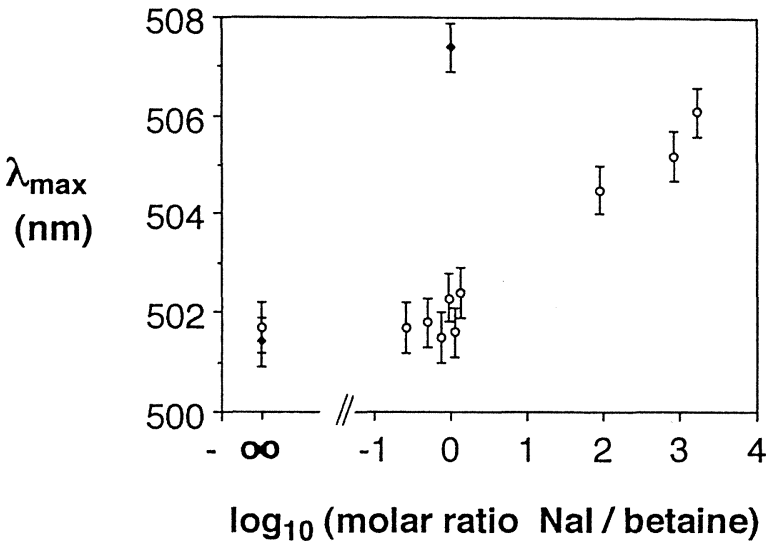

Fig.3 Absorbance maximum $\lambda_{\max }$ of $\underline{\mathrm{Co}-3}$ in dependence of added $\mathrm{NaI}$. $\mathrm{o}=$ in aqueous solution, $\bullet=$ in bulk

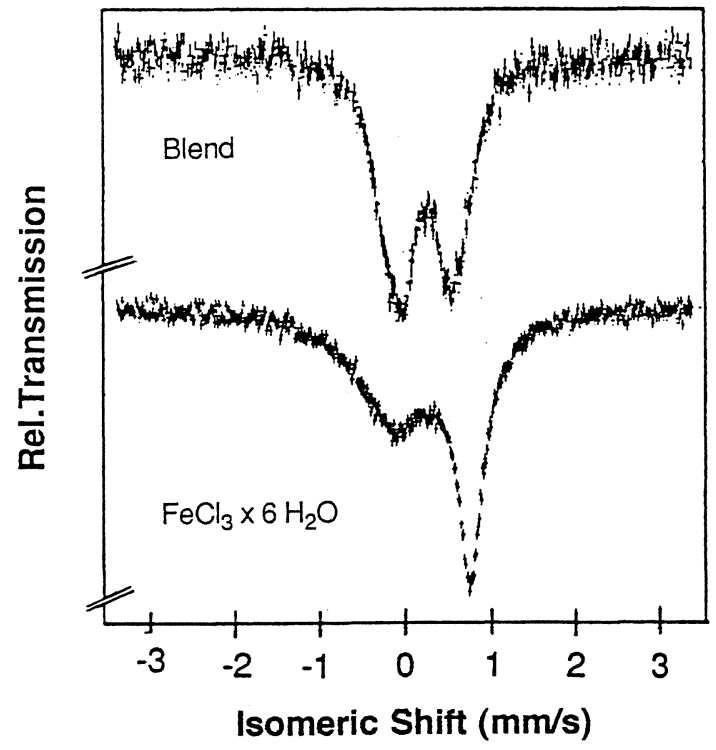

Fig.4 Mössbauer-spectra of $\mathrm{FeCl}_{3} \times 6 \mathrm{H}_{2} \mathrm{O}$ (bottom) and its equimolar blend with poly-1 (top). Both samples are prepared identically by lyophilization. 
blend and of the blend show major differences in isomeric shift and quadrupole splitting. There is no indication for free $\mathrm{FeCl}_{3} \times 6 \mathrm{H}_{2} \mathrm{O}$, thus corroborating the $\mathrm{X}$-ray results. As additionally the signals of the polymer-salt mixtures are rather weak and broadened, the spectra point to a poorly defined position of the $\mathrm{Fe}^{3+}$ ions in the blends.

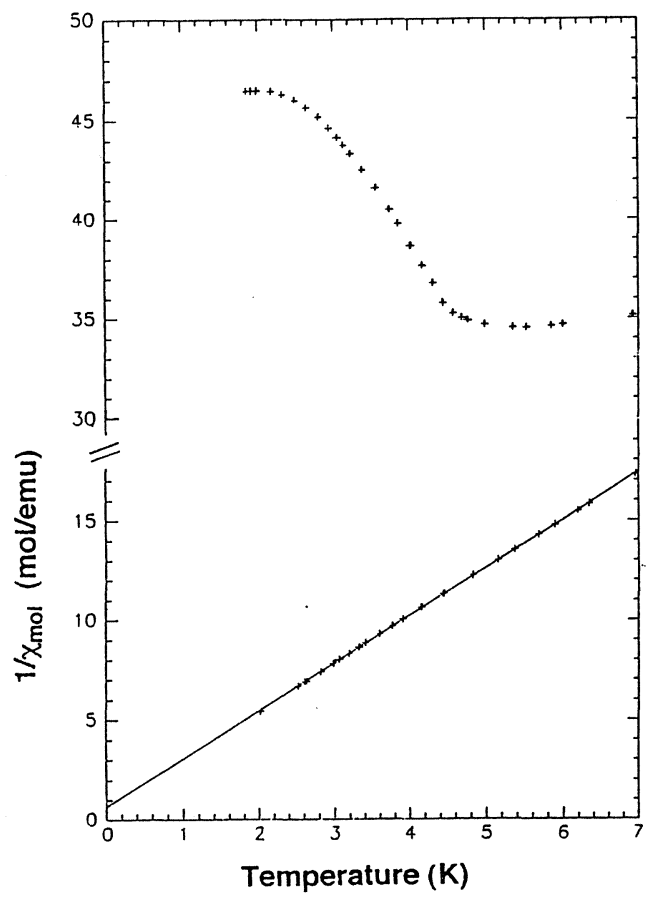

Fig.5 Temperature dependence of magnetic susceptibility $\chi$ of $\mathrm{CuCl}_{2} \times 2 \mathrm{H}_{2} \mathrm{O}$ (top) and its equimolar blend with poly-1 (bottom); units: 1emu=10-6ergOe-2 $\mathrm{mole}^{-1}$ $=10^{-5} \mathrm{~J} \cdot \mathrm{T}^{-2} \mathrm{~mole}^{-1}$. Both samples are prepared identically by lyophilization of aqueous solutions (data taken from Ref.11). 
As many of the salts used contain paramagnetic cations, magnetic measurements of the blends (Refs.11, 20) can give some clues to the structure of the blends as well. E.g., $\mathrm{CuCl}_{2} \times 2 \mathrm{H}_{2} \mathrm{O}$ and $\mathrm{CuBr}_{2}$ are paramagnetic materials at high temperatures, and antiferromagnetic ones at low temperature (Fig.5 top). In contrast, no paramagnetic-antiferromagnetic phase transitions are observed for the blends, and the extrapolated paramagnetic Curie-temperatures are $0 \mathrm{~K} \pm 0.5 \mathrm{~K}$ (Fig.5 bottom). Indicating negligible interactions between the paramagnetic ions, this result points to a "solution" of individual cations in the polymer matrix.

\section{CONCLUSIONS}

Homogeneous blends can be prepared from zwitterionic polymers and many salts of transition metals in even much more than stoichiometric amounts. The detailed structure of the blends is unclear yet, as the various analytical techniques used can be applied only in selected cases. Nevertheless, the results suggest a disordered solution of individual inorganic ions in the close vicinity of the polymer bound betaine groups. The good miscibility of polyzwitterions and inorganic salts enables thus the preparation of organicinorganic hybrid materials with many potentially interesting properties.

\section{ACKNOWLEDGEMENT}

The authors are indebted to the many colleagues of the SFB262 contributing with technical support and stimulating discussions to the study. Particular thanks are due to: M.Paudler and H.Möhwald, ellipsometry; J.Ensling and P.Gütlich, magnetic measurements and Mössbauer spectra; R.Zentel, X-ray facilities (all Dept.of Chemistry, Universität Mainz), J.Andres and M.Steiner, magnetic measurements (Dept. of Physics, Universität Mainz); N.Egger and H.W.Spiess, solid-state NMR; E.W.Fischer and M.Stamm, $\mathrm{X}$-ray facilities (all MPI für Polymerforschung, Mainz). The work was supported by grants from Materialwissenschaftliches Forschungszentrum Mainz and Deutsche Forschungsgemeinschaft, SFB 262. 


\section{REFERENCES}

(1) B. M. Novak, Adv.Mater. 5, 422 (1993)

(2) J. C. Salamone, W. C. Rice, "Polyampholytes" in: "Encyclopedia of Polymer Science and Technology" (J.I.Kroschwitz Ed.), 2nd Ed., Vol.11, 514pp, WileyInterscience, New York 1988

(3) A. Mathis, Y. L. Zheng, J.C. Galin, Makromol.Chem., Rapid Commun. 7, 333 (1986)

(4) M. Galin, E. Marchal, A. Mathis, B. Meurer, Y. M. Monroy Soto, J. C. Galin, Polymer 28, 1937 (1987)

(5) P. Köberle, A. Laschewsky, T. D. Lomax, Makromol.Chem., Rapid Commun. 12, 427 (1991)

(6) P. Köberle, A. Laschewsky, Macromolecules, 27, 2165 (1994)

(7) A. Laschewsky, I. Zerbe, Polymer 32, 2070 (1991)

(8) Organikum, 16th Ed., p.539 and p.549, VEB Deutscher Verlag der Wissenschaften, Berlin 1986

(9) P. Gütlich, R. Link, A. Trautwein, "Mössbauer-spectroscopy and Transition Metal Chemistry", in: Inorganic Chemistry Concepts, vol. 3, Springer-Verlag, Heidelberg 1978

(10) M. Paudler, Thesis 1993 (Universität Mainz)

(11) J. Andres, Diplomarbeit 1992 (Universität Mainz)

(12) N.Egger, Thesis 1992 (Universität Mainz)

(13) V. M. Monroy Soto, J. C. Galin, Polymer 25, 121 (1984)

(14) P.Köberle, A.Laschewsky, V.V.Tsukruk, Makromol.Chem. 193, 1815 (1992)

(15) V. Tsukruk, N. Mischenko, P. Köberle, A. Laschewsky, Makromol. Chem. 193, 1829 (1992)

(16) M. Paudler, P. Köberle, unpublished

(17) N.Egger, P. Köberle, A.Laschewsky, unpublished

(18) A. Dobry, J.Phys.Chim. 50, 49 (1953)

(19) J. Ensling, P.Gütlich, P.Köberle, A.Laschewsky, unpublished

(20) J. Andres, P. Köberle, M.Steiner, A.Laschewsky, to be published 